nature.com/yagpxx) retrieved in a PubMed search of open-access articles using the key words 'biomarker discovery' for the years 2004 and 2009. More than half of these contained no information about the biospecimens used. Four papers on biomarker discoveries published in Nature in 2009 contained insufficient specimen data.

Leading journals are trendsetters when it comes to defining publication criteria. For example, for some 15 years they have required statements on ethical review boards and informed consent; a biomedical paper without this information would be unthinkable today. To uphold standards, all journals should insist on full details of biobanked specimens (including medication, transportation, processing and storage).

Thousands of potential biomarkers are reported every year. Biobankers should collect complete information on specimens and pass it on to researchers to include in their publications.

Daniel Simeon-Dubach, Aurel Perren Biobank-Suisse, Bern, Switzerland.

daniel.simeon-dubach@biobanksuisse.ch

\section{Some more biofuel lessons from Brazil}

Marcia Moraes highlights lessons from Brazil's experience as a biofuel producer (Nature 474, S25; 2011), but some important ones are missing if production is to meet social and environmental standards.

First, treat the workforce consistently, and well. In some regions, sugar-cane workers are well paid, but in others notably in west-central and northeastern Brazil - they do not have proper contracts and conditions are appalling.

Second, include small-scale farmers, who have been excluded from Brazil's ethanol sector since it started 35 years ago, on the grounds of economic inefficiency. Follow the example of its national programme for biodiesel, which promotes partnerships between the oilseed industry and small

farmers and peasants.

Third, follow environmental

laws. Sugar-cane farms preserve only $11 \%$ of their land as forest (Brazilian Institute of Geography and Statistics Censo Agropecuário 2006 IBGE; 2009), although the Forest Code legislation stipulates that at least $20 \%$ should be forested. Even if the Brazilian government revises the law to reduce that percentage, sugar-cane farms will not have sufficient natural reserves to meet the legislation.

Despite much opposition, sugar-cane production has already been prohibited in the Amazon and Pantanal regions, even while deforestation proceeds unabated in the biodiversity hot spots of the Cerrado biome and the mesophytic Atlantic rainforest.

Rafael Feltran-Barbieri,

Ricardo Abramovay, Jean Paul Metzger University of Sao Paulo, Brazil. rafaelfb@usp.br

\section{Monitoring ash clouds for aviation}

To minimize airport closures caused by volcanic ash, aviation authorities should make more use of methods that are now available for measuring airborne particles.

Optical particle-counter (OPC) instruments were used to measure dust pollution during Iceland's Grímsvötn volcano eruption in May this year, after a trial last year in Eyjafjallajökull's ash plume. The data were used by Isavia, the country's airnavigation services provider, to help in decision-making.

OPC instruments measure airborne concentrations of three different size classes of particulate matter components and total suspended particles, every 6 seconds. The instruments were mounted on a light, slowflying, piston-engine aircraft after calibration in wind-tunnel experiments with volcanic ash.

As Grímsvötn erupted, OPC results were quickly dispatched to the local meteorological office and to Isavia. This helped to keep Keflavik International Airport open for longer than expected, resulting in large savings for the airline companies.

Other European aviation authorities are considering similar operations. Also, universities in Iceland and Japan are considering using OPC measurements to improve modelling of ash-cloud events. Jónas Elíasson University of Iceland, Reykjavik, Iceland.

Asgeir Palsson Isavia, Reykjavik Airport, Iceland.

Konradin Weber Düsseldorf University of Applied Sciences, Germany.

konradin.weber@fh-duesseldorf.de

\section{Humility needed in decision-making}

Daniel Gilbert maintains that people generally make bad decisions on risk issues, and suggests that communication strategies and education programmes would help (Nature 474, 275-277; 2011). This version of the deficit model pervades policy-making and branches of the social sciences.

In this model, conflicts between expert and public perceptions of risk are put down to the difficulties that laypeople have in reasoning in the face of uncertainties rather than to deficits in knowledge per se. There are three problems with this stance.

First, it relies on a selective reading of the literature.

Evolutionary psychologists have a more positive view of people's capacity for statistical reasoning (see, for example, L. Cosmides and J. Tooby Cognition 58, 1-73; 1996), arguing that many putative reasoning 'errors' may be nothing of the sort.

Second, it rests on some bold extrapolations. For example, it is not clear how the biases Gilbert identifies in the classic 'trolley' experiment play out in the real world. Many such reasoning 'errors' are mutually contradictory - for example, people have been accused of both excessive reliance on and neglect of generic 'baserate' information to judge the probability of an event. This casts doubt on the idea that they reflect universal or hard-wired failings in cognition.

The third problem is the presentation of rational choice theory as the only way of deciding how to handle risk issues.

Alternative decision logics, from the precautionary principle to deontology, are reduced to mere reasoning fallacies. Yet to be concerned with fundamental rights, moral obligations (deontology) and worst-case scenarios (precaution) is not pathological. To treat it as such, as Gilbert and others do (see, for example, C. R. Sunstein Behav. Brain Sci. 28, 531-542; 2005), seems myopic.

Given that many modern risk crises stem from science's inability to foresee the dark side of technological progress, a little humility from the rationality project wouldn't go amiss.

Brian H. MacGillivray, Nick

F. Pidgeon Cardiff University, Cardiff, UK. macgillivraybh@cardiff.ac.uk

\section{Tweet to collaborate with poorer nations}

Romain Murenzi proposes ways to improve opportunities for young scientists in the developing world (Nature 474, 543; 2011). In addition to these, social media could help to consolidate relationships with colleagues in technologically more advanced countries, and in greater numbers than travelling fellowships allow.

Sites such as Facebook and Twitter were instrumental in this year's topplings of North African dictatorships. They have also been used by Western agencies to support postgraduate education of medical interns in the Middle

East and sub-Saharan Africa (A. E. T. Finlayson et al. J. Telemed. Telecare. 16, 181-184; 2010).

A network of trusted scientists using these tools could mentor ambitious investigators in regions where free speech and unrestrained critical inquiry are novelties.

Faisal R. Ali University of

Manchester, UK.

f.r.ali.01@cantab.net

Alexander E. T. Finlayson

University of Oxford, UK. 